\title{
Phenotypic alterations in Rb pathway have more prognostic influence than p53 pathway proteins in oral carcinoma
}

\author{
R Jayasurya ${ }^{1}, K_{M}$ Sathyan ${ }^{1}, \mathrm{~K}$ Lakshminarayanan ${ }^{2}$, Thomas Abraham ${ }^{1}$, KR Nalinakumari ${ }^{3}$, \\ Elizabeth K Abraham ${ }^{2}$, M Krishnan Nair ${ }^{4}$ and S Kannan ${ }^{1}$ \\ ${ }^{1}$ Division of Cancer Research, Regional Cancer Centre, Thiruvananthapuram, Kerala, India; ${ }^{2}$ Division of \\ Cytopathology, Regional Cancer Centre, Thiruvananthapuram, Kerala, India; ${ }^{3}$ Division of Dental Surgery, \\ Regional Cancer Centre, Thiruvananthapuram, Kerala, India and ${ }^{4}$ Division of Radiation Oncology, Regional \\ Cancer Centre, Thiruvananthapuram, Kerala, India
}

\begin{abstract}
The two well-defined pathways that are shown to be prominently altered in a variety of cancers are the cell cycle regulatory pathways led by either p53 or Rb genes. The present study is undertaken to find the pathway that is more altered in oral carcinoma at protein level, with special emphasis on its prognostic significance. The expression pattern of key molecules of the Rb and p53 pathways, such as Rb, cyclin D1, CDK4, p16, p53, p21 and Bcl-2 and the proliferative marker PCNA were analysed in 348 oral carcinoma specimens by immunohistochemical technique. The expression index of these molecules and various clinicopathological factors were statistically correlated with treatment end points to assess its prognostic efficacy after following up these patients up to a maximum of 48 months with a median of 23 months. Rb pathway proteins, $\mathbf{R b}$ $(P=0.016)$, cyclin $D 1(P=0.0001)$ and p16 $(P=0.012)$ showed significant association with disease-free survival, and p16 $(P=0.041)$ and cyclin $D 1(P=<0.0001)$ with the overall survival. Among p53 pathway proteins studied, only p53 expression index showed association with both disease-free survival and overall survival. Multivariate analyses confirmed that the biological variables, cyclin D1 and p16 and the clinical variable, 'stage of disease' were independent predictors of disease-free survival and overall survival. Subgrouping of the patients on the basis of p16 and cyclin D1 expression revealed that the subgroup having downregulation of p16 and overexpression of cyclin D1 exhibited the worst disease-free survival and overall survival compared to the other subgroups. The present data showed that disabling of the Rb and p53 pathways were frequent events in oral carcinoma. The study also demonstrated that the Rb pathway proteins are comparatively more important than p53 pathway proteins for the prognostication of oral carcinoma patients. The combined evaluation of p16 and cyclin D1 in oral carcinoma could identify a group of patients with the worst survival who might therefore need alternate or more intense treatment strategies.
\end{abstract}

Modern Pathology (2005) 18, 1056-1066. doi:10.1038/modpathol.3800387; published online 25 February 2005

Keywords: oral carcinoma; cell cycle; prognosis; p53; cyclin D1; p16; Rb

Oral cancer is one of the 10 most common cancers in the world and is commonest in India and other south-east Asian countries. ${ }^{1}$ In India, oral cancer is highly prevalent, comprising a large fraction of all malignancies, due to the habit of tobacco chewing alone or with betel quid, which is commonly observed in the population. ${ }^{2}$ Although recent advances have reduced the morbidity of oral cancer,

Correspondence: Dr S Kannan, Division of Cancer Research, Regional Cancer Centre, Thiruvananthapuram - 695 011, Kerala, India.

E-mail: kannan@rcctvm.org

Received 2 November 2004; revised 5 January 2005; accepted 7 January 2005; published online 25 February 2005 the 5-year survival rate for these patients has remained almost unchanged at $\sim 50 \%$ for the last 30 years. ${ }^{3}$ Oral cancers are highly heterogeneous in nature regarding site, biology and treatment response. In clinical practice, the treatment planning and prognosis of oral cancer is mainly based on the TNM classification; however, there is increasing evidence that in its current form, it is probably insufficient to predict the clinical outcome of patients with oral carcinoma. Therefore, it is important to look for new biological prognostic markers that might add information about the aggressiveness of tumours and treatment response. A number of studies have revealed the pivotal role played by proto-oncogenes and tumour suppressor 
genes in cell cycle regulation and apoptosis, indicating their aberrant expression during the course of evolution of various human cancers. ${ }^{4}$

The $\mathrm{Rb}$ pathway and the p53 pathway are two important, interconnected biochemical pathways frequently perturbed in human cancer (Figure 1). It has been reported that more than $90 \%$ of oral tumours had at least one abnormality affecting either $\mathrm{Rb}$ or cyclin $\mathrm{D} 1$ or $\mathrm{p} 16^{5}$ and the data suggest that this pathway is a near universal target in oral carcinogenesis. After activation by cyclin D1, CDK4 or CDK6 is able to phosphorylate the $\mathrm{Rb}$ protein, leading to its functional inactivation and release of transcription factors necessary for entry into $S$ phase and cell cycle progression. ${ }^{6,7}$

p53 is reported to play a key role to ensure genomic integrity. In order to facilitate this, apoptosis should be tightly coupled to cell cycle checkpoints. $^{7}$ In response to a variety of types of DNA damage, the p53 tumour suppressor gene product is activated and regulates a number of downstream cellular processes such as cell cycle arrest, apoptosis and DNA repair. p53 was shown to mediate the arrest of cells at the G1/S boundary mainly by transactivating p21 gene (Figure 1), which inhibits the function of the CDK4-cyclin D complex. ${ }^{8}$ The proapoptotic effects of p53 are mediated by a variety of mechanisms, including the downregulation of bcl-2 and the induction of proapoptotic members of the bcl-2 family.

Comprehensive studies of the clinical significance of these perturbations in the components of $\mathrm{Rb}$ and p53 pathways have not been performed in oral carcinoma. In the present study, we have investigated the expression of $\mathrm{Rb}$ pathway proteins like $\mathrm{Rb}$, cyclin D1, CDK4 and p16, and p53 pathway proteins, p53, p21 and bcl-2 in a large cohort of oral carcinoma patients. We have also analysed the expression of a proliferation marker, Proliferating Cell Nuclear Antigen (PCNA), in these samples. The expression data were then correlated with treatment outcome to determine their potential prognostic value.

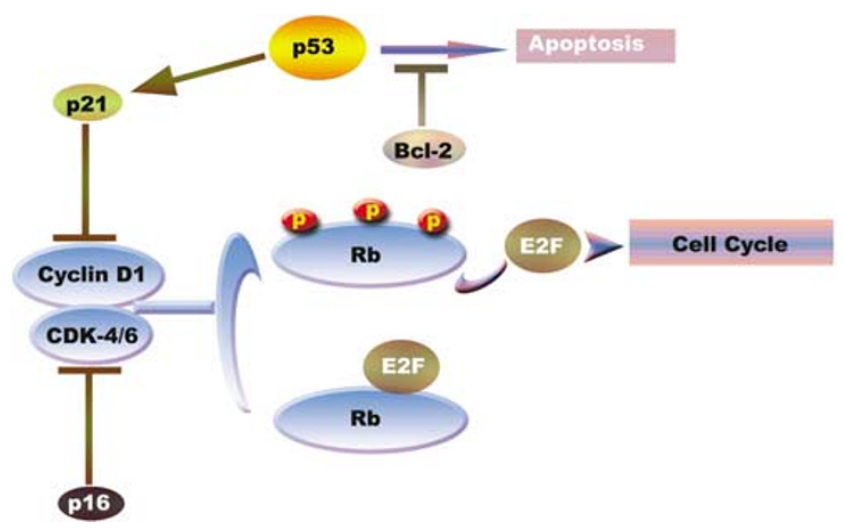

Figure 1 Flow diagram showing the role of major components of p53 and $\mathrm{Rb}$ pathways in cell cycle regulation.

\section{Materials and methods}

For the present study, 348 consecutive (previously untreated) patients with oral cancer attending an outpatient clinic of the Regional Cancer Centre, Thiruvananthapuram were included, after obtaining the Ethics Committee's approval. The clinicopathological characteristics of these cases are summarized in Table 1. Clinical staging of the disease was carried out according to the UICC criteria. The mean ages of male and female patients were $60 \pm 10$ and $59 \pm 10$ years, respectively. There were 129 female $(37 \%)$ and 219 male patients (63\%). Radiotherapy was the sole treatment modality in 165 patients, surgery alone was carried out in 23 patients, 94 patients received combined XRT and surgery and the remaining cases (66) received adjuvant chemotherapy along with radiotherapy or surgery. Clinical follow-up of all these patients was carried out until death or up to a maximum of 48 months with a median follow-up of 23 months.

\section{Immunohistochemistry}

Standard avidin-biotin complex (ABC) method was employed for immunohistochemical studies, as described earlier by us. ${ }^{9}$ Briefly, 5 - $\mu$ m-thick tissue sections were cut from buffered formalin-fixed, paraffin-embedded tissues. Sections were deparaffinized in xylene and rehydrated. Microwave pretreatment in citrate buffer was performed to retrieve the epitopes. After blocking the nonspecific sites, the sections were incubated overnight at $4^{\circ} \mathrm{C}$ with optimally diluted respective primary antibodies: $\mathrm{Rb}$ (clone IF8), cyclin D1 (clone DCS6), CDK4 (clone DCS35), p16 (clone ZJ14), p53 (clone DO7 and PAb240), p21 (clone DCS60.2), Bcl-2 (clone 4D7.6) and PCNA (clone PC10). All the antisera were purchased from Neomarkers, CA, USA. Negative controls (with diluted non-immune mouse sera instead of primary antibody) were also run with each sample. The antibody-bound sites were visualized using an avidin-biotin-immunoperoxidase system (VectaElite, Vector Laboratories Inc., Burlingame, CA, USA) with diaminobenzidine with nickel intensification (Vector Laboratories Inc., Burlingame, CA, USA) as chromogen and counter stained with haematoxylin. The surrounding stromal cells and adjacent normal epithelia present in the sections served as internal controls.

\section{Immunohistochemical Staining Evaluation}

The immunostained sections were examined microscopically by two of the authors without the knowledge of the patients' clinical data or treatment outcome. The intensity of staining was evaluated using a four-point semiquantitative scale: $0=$ negative, $2=$ mild, $4=$ moderate, $6=$ intense. Besides the staining intensity, the percentage of positive 
Table 1 Clinicopathological characteristics of the patients

\begin{tabular}{|c|c|}
\hline Characteristics & No. $(\%)$ \\
\hline \multicolumn{2}{|l|}{ Sex } \\
\hline Male & $219(63)$ \\
\hline Female & $129(37)$ \\
\hline \multicolumn{2}{|l|}{ Age (years) } \\
\hline$<45$ & $42(11.9)$ \\
\hline $45-60$ & $152(43.8)$ \\
\hline$>60$ & $154(44.3)$ \\
\hline \multicolumn{2}{|l|}{ Habits $^{\mathrm{a}}$} \\
\hline None & $16(4.6)$ \\
\hline Chewing only & $113(32.5)$ \\
\hline Smoking only & $12(3.4)$ \\
\hline Chewing+smoking & $31(8.9)$ \\
\hline Chewing+alcohol & $22(6.3)$ \\
\hline Chewing+smoking+alcohol & $69(19.8)$ \\
\hline Others & $70(20.1)$ \\
\hline NA & $15(4.3)$ \\
\hline \multicolumn{2}{|l|}{ Site of lesion } \\
\hline Tongue & $95(27.2)$ \\
\hline Other than tongue & $253(72.7)$ \\
\hline \multicolumn{2}{|l|}{ Tumour (T) - status } \\
\hline T1 & $52(15.2)$ \\
\hline $\mathrm{T} 2$ & 135 (39.5) \\
\hline T3 & 49 (14.1) \\
\hline $\mathrm{T} 4$ & $106(31.0)$ \\
\hline NA & 6 \\
\hline \multicolumn{2}{|l|}{ Nodal (N) - status } \\
\hline No & $223(65.2)$ \\
\hline N1 & $100(28.7)$ \\
\hline N2 & $16(4.7)$ \\
\hline N3 & $3(0.9)$ \\
\hline NA & 6 \\
\hline \multicolumn{2}{|l|}{ Composite stage } \\
\hline Stage I & $45(13.2)$ \\
\hline Stage II & $95(27.8)$ \\
\hline Stage III & $91(26.6)$ \\
\hline Stage IV & $111(32.5)$ \\
\hline NA & 6 \\
\hline \multicolumn{2}{|l|}{ Histopathology } \\
\hline Well-differentiated squamous cell carcinoma & $101(29.0)$ \\
\hline $\begin{array}{l}\text { Moderately differentiated squamous cell } \\
\text { carcinoma }\end{array}$ & $210(60.3)$ \\
\hline Poorly differentiated squamous cell carcinoma & $17(4.9)$ \\
\hline Verrucous carcinoma & $19(5.5)$ \\
\hline Spindle cell carcinoma & $1(0.3)$ \\
\hline \multicolumn{2}{|l|}{ Mode of treatment } \\
\hline Radiotherapy & $165(47.4)$ \\
\hline Surgery & $23(6.6)$ \\
\hline Chemotherapy & $7(2.0)$ \\
\hline Radiotherapy+surgery & $94(27.0)$ \\
\hline Chemotherapy+external radiotherapy & $32(9.2)$ \\
\hline Chemotherapy+external radiotherapy+surgery & $27(7.8)$ \\
\hline \multicolumn{2}{|l|}{ Disease-free survival } \\
\hline Good & $175(50.3)$ \\
\hline Poor & $170(48.9)$ \\
\hline Not known & $3(0.9)$ \\
\hline \multicolumn{2}{|l|}{ Overall survival } \\
\hline Alive & $156(44.8)$ \\
\hline Dead & $165(47.4)$ \\
\hline Not known & $27(7.8)$ \\
\hline
\end{tabular}

NA $=$ not available

${ }^{a}$ Patients having oral habits exceeding 1 year were only considered as having a particular habit. cells was also noted. For assessing the positivity, the cells seen at the invading tumour front or the deep malignant islands were considered. For analysis, the results were expressed as expression index, that is, the product of percentage of positivity and score of the staining intensity seen in the majority of the cells. For Bcl-2, staining intensity alone was considered as its expression was only confined to the cytoplasm of basaloid cells. For analysis, median of expression index was taken as cutoff point to dichotomize the data. The expression index values above the median were categorized as overexpression and median value or values below the median were considered as low expression.

\section{Statistical Analysis}

Statistical analysis between clinico-biological factors and end points was carried out using the logrank test. The end points considered in the present study were disease-free survival and overall survival. Disease-free survival status was scored as poor or good. Poor disease-free survival status was defined as the retention of treated lesion even after the completion of treatment or the presence of recurring disease in an initially well-responded lesion. Overall survival was scored as either dead or alive at the last follow-up, irrespective of the disease status. Predictive variables in univariate analysis were then incorporated into multivariate analyses using the Cox's proportional hazard model by applying forward stepwise logistic regression to identify the factors that were independent predictors of the survival end points. The hazard ratio and $95 \%$ confidence interval of hazard ratio were calculated. Disease-free survival and overall survival curves were prepared by the Kaplan-Meier method. The significance of the differences between the curves was calculated using the log-rank test. A two-tailed $P$-value $<0.05$ was considered 'statistically significant' in all statistical analyses.

\section{Results}

\section{Expression Pattern of Rb and p53 Pathway Proteins}

Immunohistochemical expression pattern was determined by evaluating both the staining intensity and the percentage of positive cells. Representative pictures of immunohistochemical staining are shown in Figure 2. The immunohistochemical staining patterns of $\mathrm{Rb}$ and $\mathrm{p} 53$ pathway proteins in normal and malignant epithelium are summarized in Table 2. All the examined proteins (except $\mathrm{p} 16)$ of $\mathrm{Rb}$ and $\mathrm{p} 53$ pathways were overexpressed in tumour cells. p16 exhibited a downregulation in the majority of malignant cases (Figure 2c). Except Bcl2 , all other proteins studied are primarily located in the nucleus, but bcl-2 expression was mainly 

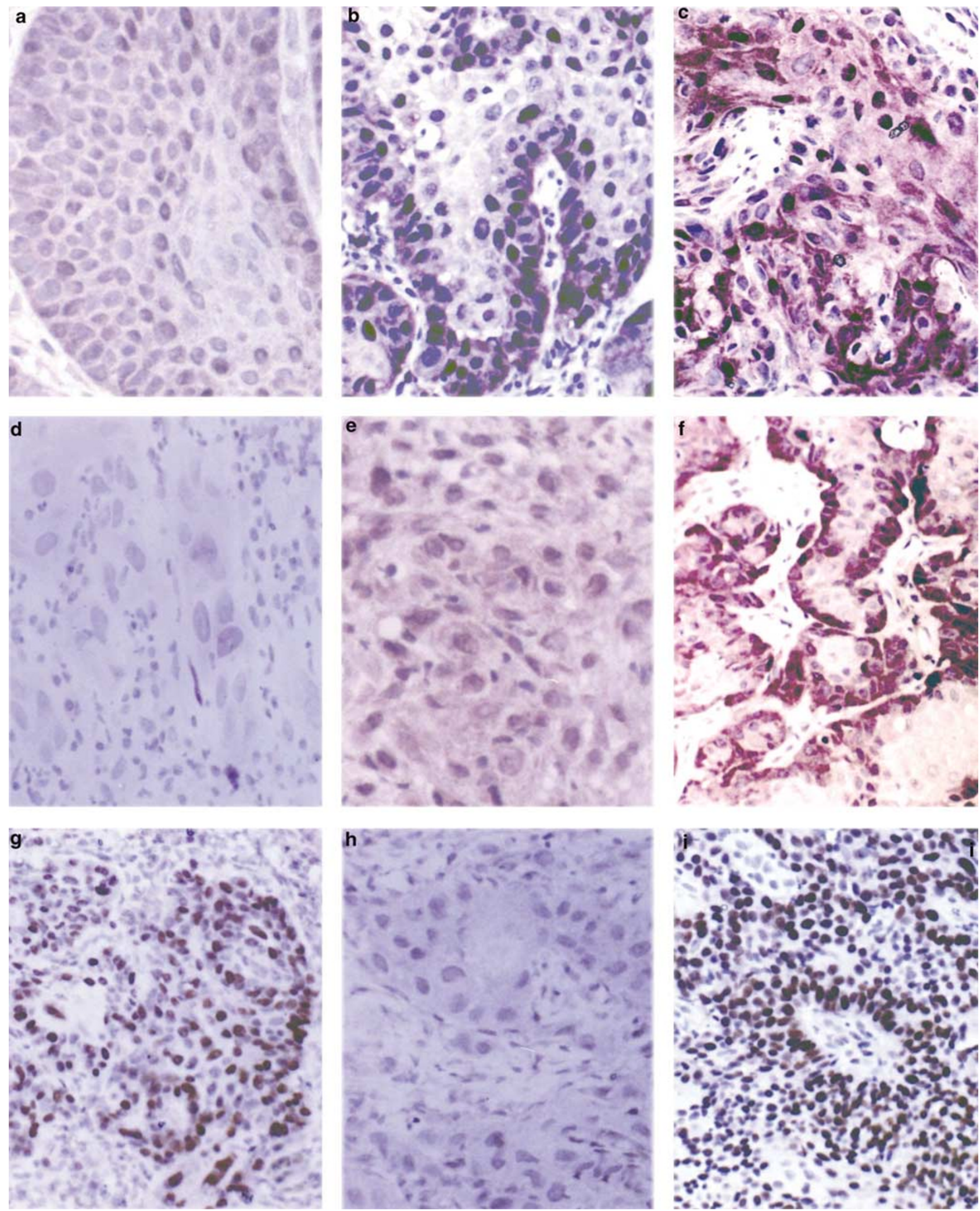

Figure 2 Expression pattern of cyclin D1, p16 and p53 in oral carcinomas. (a) A few nuclei showed mild staining for cyclin D1. (b) Cells in the invading margin showed moderate nuclear and cytoplasmic staining for cyclin D1. (c) Almost all the cells showed intense nuclear and moderate cytoplasmic staining for cyclin D1. (d) Negative staining for p16. (e) Moderate nuclear and cytoplasmic positivity for p16. (f) Intense nuclear and cytoplasmic staining for p16 in peripheral basaloid cells. (g) Intense p53 nuclear expression with antibody clone DO-7. (h) Same sample having almost negative expression with antibody clone PAb240. (i) Moderate expression of p53 in plenty of malignant cells with antibody clone PAb240. 
Table 2 Immunohistochemical staining patterns of various protein markers

\begin{tabular}{|c|c|c|c|c|c|}
\hline \multirow[t]{2}{*}{ Protein } & \multirow{2}{*}{$\begin{array}{l}\text { Staining localization in } \\
\text { tumour cells }\end{array}$} & \multicolumn{2}{|c|}{ Staining $(\%)^{\mathrm{a}}$} & \multirow{2}{*}{$\begin{array}{l}\text { Median of } \\
\text { expression } \\
\text { index }\end{array}$} & \multirow[t]{2}{*}{ Staining pattern in normal oral epithelium } \\
\hline & & Negative & Intense & & \\
\hline p53-DO-7 & Nuclear & 7.6 & 67 & 148 & Mild staining seen in a few basal cells \\
\hline p53-Pab240 & Nuclear & 44.4 & 28.4 & 26 & Negative in all the normal cells \\
\hline $\mathrm{p} 21$ & Nuclear & 3.5 & 61.9 & 88 & $\begin{array}{l}\text { Moderate nuclear staining in } 1 \text { or } 2 \text { layers of lowermost } \\
\text { spinal cells }\end{array}$ \\
\hline bcl-2 & Cytoplasm & 38.8 & 27.1 & 20 & Mild cytoplasmic staining seen in basal cells \\
\hline Cyclin D1 & Nucleus and cytoplasm & 7.3 & 49.1 & 103 & $\begin{array}{l}\text { Scattered. Mild nuclear staining seen in basal-parabasal } \\
\text { layers }\end{array}$ \\
\hline Cdk4 & Nucleus and cytoplasm & 17.9 & 17.3 & 60 & $\begin{array}{l}\text { Scattered. Mild nuclear staining seen in basal-parabasal } \\
\text { layers }\end{array}$ \\
\hline p16 & Nucleus and cytoplasm & 64.3 & 15.8 & 0 & Scattered. Mild staining seen in spinal cells \\
\hline $\mathrm{Rb}$ & Nuclear & 2.9 & 78.7 & 169 & Moderate staining seen in nuclei of parabasal cells \\
\hline PCNA & Nuclear & 0 & 71 & 198 & Scattered. Intense staining in basal-parabasal cells \\
\hline
\end{tabular}

${ }^{a}$ Staining intensity was graded as negative, mild, moderate and intense. Percentage of patients showing the extreme grades are only shown in the table.

confined to the cytoplasm of tumour cells in the invading margin. Cyclin D1 and p16 also showed some degree of expression in cytoplasm (Figure 2af). Expression pattern of p53 was assessed with two clones of monoclonal antibodies, DO7 and Pab240, which showed some prominent differences in expression pattern (Figure 2g-i). The staining intensity and positivity were comparatively more with DO7 than with PAb240. In all, $6.7 \%$ of cases were negative and $70.5 \%$ showed intense staining with DO7 clone. However, when PAb240 clone was used, $41.2 \%$ of cases showed negative staining and only $32 \%$ of cases showed intense staining. The expression of PCNA was not confined to the basaloid cells, but was also seen in differentiating squamous cells. Poorly differentiated tumours showed higher PCNA expression compared to well-differentiated ones.

\section{Association of Rb and p53 Pathway Proteins with Survival of the Patients}

Disease-free survival

The clinico-biological variables that had significant relation with disease-free survival and overall survival in univariate analyses are summarized in Tables 3 and 4, respectively. The level of expression of $\mathrm{Rb}$ pathway proteins, Rb, cyclin $\mathrm{D} 1$ and p16 showed significant association with diseasefree survival. Overexpression of cyclin D1 and Rb and low expression of p16 showed significant association with reduced disease-free survival. The other Rb pathway proteins studied did not exhibit any significant difference with disease-free survival. Kaplan-Meier survival curves for the patients with low or high expression of cyclin D1 and p16 are presented in Figure $3 a$ and b, respectively.
Table 3 Clinico-biological factors showed significance with disease-free survival in univariate analysis

\begin{tabular}{|c|c|c|c|c|c|}
\hline \multirow[t]{2}{*}{ Factors } & \multicolumn{5}{|c|}{ Disease-free survival } \\
\hline & Good & Poor & Log-rank & P-value & $\begin{array}{l}\text { Relative } \\
\text { risk }\end{array}$ \\
\hline \multicolumn{6}{|l|}{$p 16$} \\
\hline Low & 101 & 118 & & & \\
\hline High & 72 & 49 & 6.29 & 0.012 & 0.58 \\
\hline \multicolumn{6}{|l|}{ Cyclin D1 } \\
\hline Low & 105 & 64 & & & \\
\hline High & 69 & 103 & 17.73 & $<0.0001$ & 2.45 \\
\hline \multicolumn{6}{|l|}{$R b$} \\
\hline Low & 97 & 72 & & & \\
\hline High & 76 & 95 & 5.82 & 0.016 & 1.68 \\
\hline \multicolumn{6}{|l|}{ p53-DO7 } \\
\hline Low & 97 & 73 & & & \\
\hline High & 76 & 93 & 4.86 & 0.028 & 1.63 \\
\hline \multicolumn{6}{|c|}{ p53-Pab240 } \\
\hline Low & 100 & 75 & & & \\
\hline High & 70 & 94 & 7.42 & 0.006 & 1.79 \\
\hline \multicolumn{6}{|l|}{ T-status } \\
\hline I & 32 & 19 & & & 1.00 \\
\hline II & 70 & 63 & & & 1.52 \\
\hline III & 28 & 21 & & & 1.26 \\
\hline IV & 40 & 66 & 12.42 & 0.006 & 2.78 \\
\hline \multicolumn{6}{|l|}{$N$-status } \\
\hline Absent & 121 & 100 & & & \\
\hline Present & 50 & 68 & 5.69 & 0.017 & 1.65 \\
\hline \multicolumn{6}{|c|}{ TNM stage } \\
\hline I & 28 & 17 & & & 1.00 \\
\hline II & 52 & 41 & & & 1.30 \\
\hline III & 47 & 43 & & & 1.51 \\
\hline IV & 43 & 68 & 11.52 & 0.009 & 2.61 \\
\hline
\end{tabular}

'Low' = low expression ( $\leq$ median of expression index); 'High' = high expression ( $>$ median of expression index). 
Table 4 Clinico-biological factors showed significance with overall survival in univariate analysis

\begin{tabular}{|c|c|c|c|c|c|}
\hline \multirow[t]{2}{*}{ Factors } & \multicolumn{5}{|c|}{ Overall survival } \\
\hline & Alive & Dead & Log-rank & $\mathrm{P}$-value & Relative risk \\
\hline \multicolumn{6}{|l|}{ p16 } \\
\hline Low & 89 & 113 & & & \\
\hline High & 64 & 49 & 4.18 & 0.041 & 0.60 \\
\hline \multicolumn{6}{|l|}{ Cyclin D1 } \\
\hline Low & 97 & 59 & & & \\
\hline High & 58 & 103 & 22.46 & $<0.0001$ & 2.92 \\
\hline \multicolumn{6}{|l|}{$R b$} \\
\hline Low & 84 & 72 & & & \\
\hline High & 69 & 90 & 3.49 & $0.062^{\mathrm{a}}$ & 1.52 \\
\hline \multicolumn{6}{|l|}{ p53-DO7 } \\
\hline Low & 88 & 74 & & & \\
\hline High & 66 & 87 & 3.86 & 0.049 & 1.57 \\
\hline \multicolumn{6}{|c|}{ p53-Pab240 } \\
\hline Low & 88 & 74 & & & \\
\hline High & 64 & 90 & 5.50 & 0.019 & 1.67 \\
\hline \multicolumn{6}{|l|}{ T-status } \\
\hline I & 31 & 15 & & & 1.00 \\
\hline II & 65 & 59 & & & 1.88 \\
\hline III & 21 & 24 & & & 2.36 \\
\hline IV & 34 & 67 & 18.98 & 0.0003 & 4.07 \\
\hline \multicolumn{6}{|l|}{$N$-status } \\
\hline Absent & 111 & 96 & & & \\
\hline Present & 41 & 68 & 6.80 & 0.009 & 1.92 \\
\hline \multicolumn{6}{|l|}{ TNM stage } \\
\hline I & 28 & 12 & & & 1.00 \\
\hline II & 48 & 40 & & & 1.94 \\
\hline III & 38 & 46 & & & 2.82 \\
\hline IV & 37 & 67 & 17.42 & 0.0006 & 4.22 \\
\hline
\end{tabular}

'Low' = low expression ( $\leq$ median); 'High' = high expression ( $>$ median).

${ }^{\mathrm{a}}$ Marginal significance.

When the possible association of p53 pathway proteins were examined, only p53 expression pattern showed significant association with disease-free survival (Table 3). Expression pattern using p53 monoclonal antibodies Pab240 $(P=0.006)$ showed more significant association compared to DO7 $(P=0.028)$. In addition, conventional clinical variables such as $\mathrm{N}$-status $(P=0.0006)$, T-status $(P=0.006)$ and stage of lesion $(0.009)$ were also significantly associated with disease-free survival.

\section{Overall survival}

In terms of the overall survival, the $\mathrm{Rb}$ pathway proteins like p16 $(P=0.041)$ and cyclin D1 $(P=<0.0001)$ showed prognostic significance in univariate analysis (Table 4). The Kaplan-Meier survival curves for low and high expression of cyclin D1 and p16 in relation to overall survival are given in Figure $4 \mathrm{a}$ and $4 \mathrm{~b}$, respectively. Among the various p53 pathway proteins studied, only p53
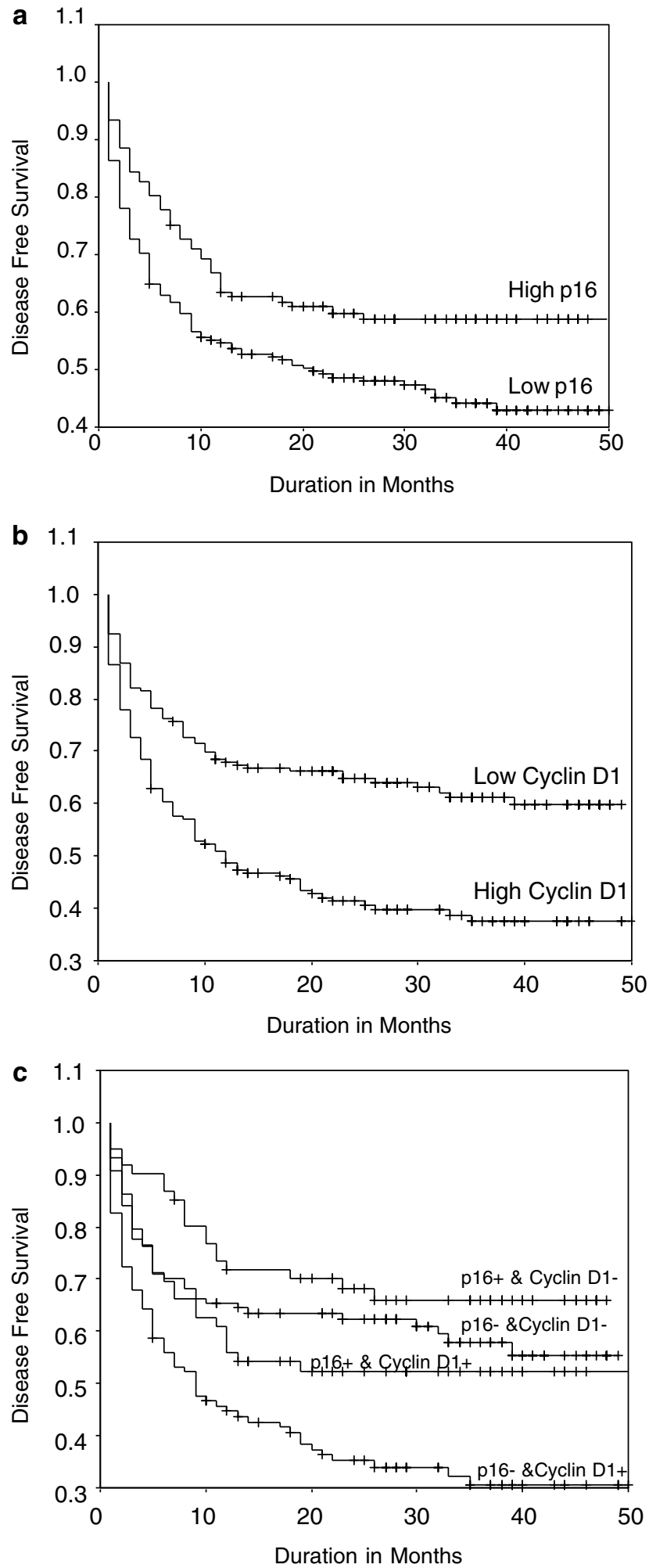

Figure 3 Kaplan-Meier curve for disease-free survival of patients with oral carcinoma stratified with expression status of p16 (a), cyclin D1 (b) and p16-Cyclin D1 combination (c) $[-=$ low expression; $+=$ high expression].

expression showed significant association with overall survival. This effect of p53 protein was seen with both monoclonal antibodies DO7 and Pab240. 

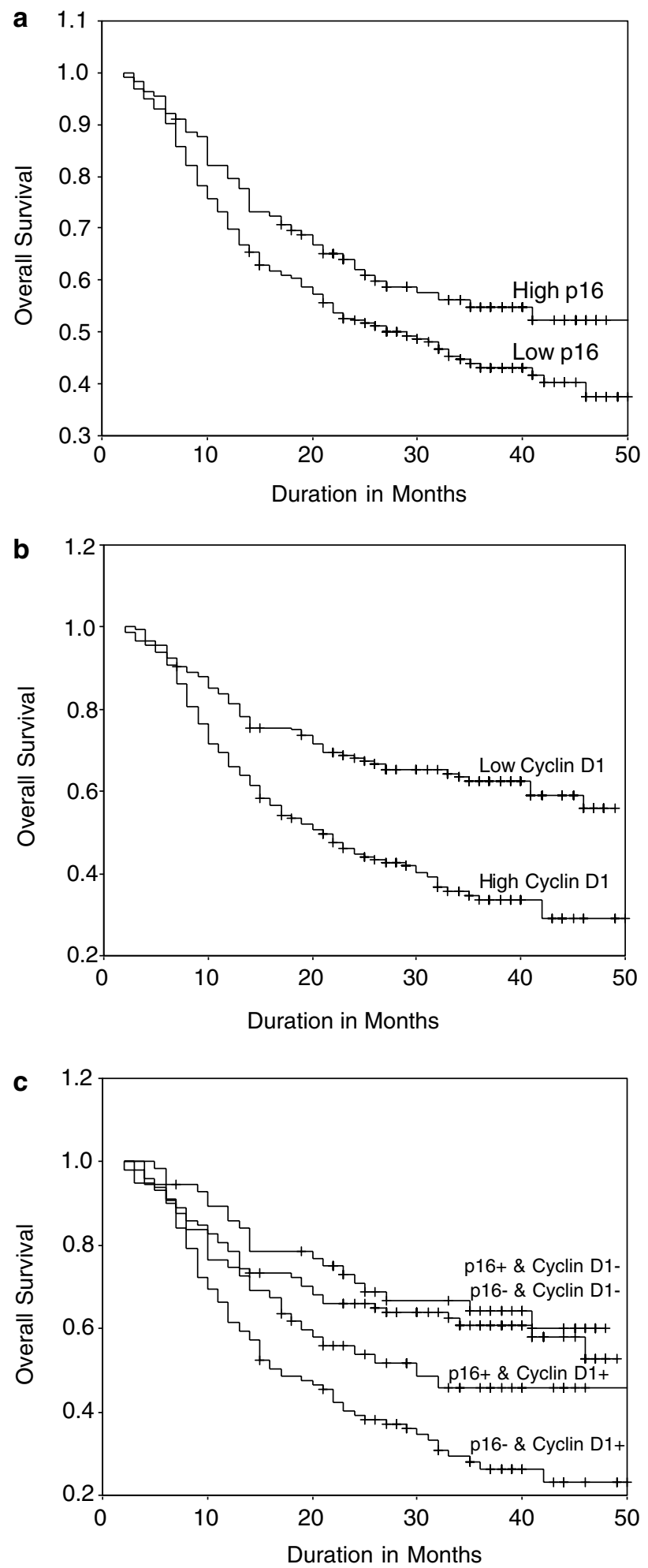

Figure 4 Kaplan-Meier curve for overall survival of patients with oral carcinoma stratified with expression status of p16 (a), cyclin D1 (b) and p16-cyclin D1 combination (c) [-=low expression; $+=$ high expression].

Overall survival was also significantly associated with $\mathrm{N}$-status $(P=0.009)$, T-status $(P=0.0003)$ and stage of disease $(P=0.0006)$.

\section{Multivariate analysis}

In multivariate Cox analysis, clinical and biological variables that showed significance in univariate analysis were selected. The markers that showed independent influence on disease-free survival and overall survival are shown in Table 5. Among the conventional clinical variables, only stage of disease was found to be an independent predictor for both disease-free survival and overall survival in these patients. Among the biological variables, $\mathrm{Rb}$ pathway proteins, cyclin D1 and p16 were found to be independent predictors of disease-free survival and overall survival in these patients. Thus, cyclin D1 and p16 expression were important biological prognostic markers for oral cancer and their influence on the survival of the patients was stronger than the other conventional clinical prognostic markers examined (Table 5).

\section{Combined Effect of Cyclin D1 and p16 Expression on Treatment Response}

Since cyclin D1 and p16 expression were found to be independent predictors of disease-free survival and overall survival, we also assessed the effect of different combinations of these two potential biomarkers on disease-free survival and overall survival. All cases were categorized into four subgroups according to cyclin D1 and p16 expression pattern. $\chi^{2}$ test was used to analyse the combined effect of the expression of these proteins on disease-free survival and overall survival. The relative risk and the percentage of poor responders in each combination and their significance are presented in Table 6 . Kaplan-Meier survival curves for the combined effect of cyclin D1 and p16 on disease-free survival and overall survival are given in Figures 3c and 4c, respectively. In all, $67.2 \%$ of cases with 'low cyclin D1 expression and high p16 expression' had good disease-free survival, whereas only $33.9 \%$ of cases with 'high cyclin D1 expression and low p16 expression' had good disease-free survival. In all, $64.9 \%$ of patients with a molecular phenotype of 'low cyclin D1 expression and high p16 expression' were alive after 48 months of follow-up, whereas only $28.7 \%$ of patients with a molecular phenotype of 'high cyclin D1 expression and low p16 expression' were alive after the same period of follow-up. The survival of the patients was intermediate for the other two subgroups. Thus, subgrouping of patients based on the expression of cyclin D1 and p16 could identify a group of patients with very poor prognosis.

\section{Discussion}

Dysregulation of the cell cycle machinery is a fundamental feature of cancer. The multistep process of oral carcinogenesis likely involves functional alterations of cell cycle regulatory members combined 
Table 5 Clinico-biological factors showed independent influence on various treatment end points in multivariate analysis

\begin{tabular}{|c|c|c|c|c|}
\hline End points and variables & Coefficient & $\mathrm{P}$-value & Hazard ratio (HR) & $95 \%$ confidence interval of $\mathrm{HR}$ \\
\hline \multicolumn{5}{|l|}{ Disease-free survival } \\
\hline Cyclin D1-overexpression vs low expression & 0.6035 & 0.0003 & 1.8285 & $1.32-2.53$ \\
\hline p16-low expression vs overexpression & 0.4745 & 0.0067 & 1.6027 & $1.15-2.29$ \\
\hline Composite stage & 0.2073 & 0.0085 & 1.2303 & $1.05-1.44$ \\
\hline \multicolumn{5}{|l|}{ Overall survival } \\
\hline Cyclin D1-overexpression vs low expression & 0.7691 & $<0.001$ & 2.1579 & $1.54-3.03$ \\
\hline p16-low expression vs overexpression & 0.3582 & 0.0461 & 1.2042 & $1.01-2.03$ \\
\hline Composite stage & 0.3103 & 0.0002 & 1.3638 & $1.16-1.61$ \\
\hline
\end{tabular}

Table 6 Relative risk and significance of different combinations of p16 and cyclin D1 expression pattern with various treatment end points

\begin{tabular}{lcccc}
\hline Combination & \multicolumn{2}{c}{ Disease-free survival } & \multicolumn{2}{c}{ Overall survival } \\
\cline { 2 - 5 } & $\begin{array}{c}\text { \% of poor } \\
\text { cases }\end{array}$ & $\begin{array}{c}\text { Relative } \\
\text { risk }\end{array}$ & $\begin{array}{c}\text { \% of dead } \\
\text { cases }\end{array}$ & $\begin{array}{c}\text { Relative } \\
\text { risk }\end{array}$ \\
\hline p16- & 54 & 1.72 & 56 & 1.67 \\
Cyclin D1+ & 60 & 2.45 & 64 & 2.92 \\
p16+/cyclin D1- & 33 & 1.00 & 35 & 1.00 \\
p16-/cyclin D1- & 41 & 1.43 & 40 & 1.22 \\
p16+/cyclin D1+ & 48 & 1.85 & 51 & 1.92 \\
p16-/cyclin D1+ & 66 & 3.99 & 71 & 4.59 \\
$\chi^{2}$ & \multicolumn{2}{c}{21.82} & \multicolumn{2}{c}{27.33} \\
$P$-value & \multicolumn{2}{c}{$<0.0001$} & \multicolumn{2}{c}{$<0.0001$} \\
\hline
\end{tabular}

'-'=Low expression ( $\leq$ median of expression index); '+'=overexpression ( $>$ median of expression index).

with escape from cellular senescence and apoptotic signalling pathways. The ability to map the signature cell cycle defects in human oral cancer is useful for early diagnosis, prognostication and biologybased therapy. ${ }^{10}$ Mutational events that disable the $\mathrm{Rb}$ pathway enforce cell proliferation and are counterbalanced by a p53-dependent apoptosis response that can eliminate incipient cancer cells. Several reports have indicated that loss or deregulated expression of several genes that have a significant role in $\mathrm{Rb}$ and p53 pathways are critical events in the evolution of oral carcinoma. ${ }^{10}$ In the present study, we analysed the expression pattern of the important members in the Rb and p53 pathway in 348 oral cancer samples and assessed their prognostic potential. The principal finding of our study is that the expression of Rb pathway proteins like cyclin D1 and p16 are independent biological prognostic markers for oral carcinoma and can supplement the conventional clinicopathological prognostic markers. The simultaneous assessment of cyclin D1 and p16 showed their potential in the identification of a subgroup with the worst prognosis. Our data have failed to establish independent prognostic roles for other proteins of the Rb and p53 pathways.
$\mathrm{Rb}$ pathway plays a crucial regulatory role in cell cycle progression. ${ }^{11,12}$ Initial inactivating phosphorylation of Rb by cyclin D-CDK4/6 complex in the mid to late G1 phase of the cell cycle releases E2F from $\mathrm{Rb}$ and, subsequently, progression of cell cycle occurs (Figure 1). Rb function may be abrogated by mutations of specific components in this pathway. Although expressions of some of these components were seen to be frequently altered in the present study, only cyclin D1 and p16 showed significant association with survival. Cyclin D1 overexpression showed significant association with poor diseasefree survival and overall survival. In previous studies, Masuda et $a l^{13}$ and Bova et $a l^{14}$ have found significant association between cyclin D1 overexpression and reduced survival in head and neck squamous cell carcinoma (HNSCC) and tongue carcinoma, respectively. The mechanism by which cyclin D1 overexpression leads to reduced survival remains unclear. Ruas and Peters ${ }^{12}$ have found that overexpression of cyclin D1 leads to the formation of more cyclin D1-CDK4/6 holoenzyme, which triggers the phosphorylation of $\mathrm{Rb}$, thereby helping to cancel its growth repressive functions. Cyclin D1 was also shown to affect the activity of various cellular transcription factors in a CDK-independent manner. ${ }^{15}$ Recently, Lamb et $a 1^{16}$ demonstrated that the pathway connecting cyclin D1 with E2F-mediated transcription is not as important as previously reported. Instead, their studies showed the existence of a functional interdependency between cyclin D1 and C/EBP. Thus, the observed association between overexpression of cyclin D1 and poor survival may have been contributed by CDK-dependent and/orindependent pathways.

Loss of functional p16 in HNSCC may be the result of homozygous deletion, promoter hypermethylation or due to mutation. ${ }^{17,18}$ In the present study, downregulation of p16 was seen in $64 \%$ of cases. High frequency of p16 downregulation has also been reported in HNSCC, in other previous studies. $^{14,19}$ The prognostic significance of p16 expression remains controversial. Pande et $a l^{19}$ and Miracca et $a l^{17}$ reported a high frequency of p16 alterations in head and neck tumours, although they failed to establish any prognostic significance for 
p16 alterations. However, in other studies, loss of p16 function has been correlated with poor prognosis in oral cancer patients. ${ }^{14,20}$ In the present study, loss of expression of p16 was found to be an independent prognostic marker for predicting the disease-free survival and overall survival in oral cancer patients. In the absence of p16 expression, p16 cannot inhibit the kinase activity of the cyclin D-CDK4/6 complex, and therefore it will inactivate $\mathrm{Rb}$ and untether $\mathrm{E} 2 \mathrm{~F}$ from $\mathrm{Rb}$. This may trigger increased cell proliferation, which may contribute to poor survival.

Although the cell cycle regulators, cyclin D1 and p16, showed significant relation with disease prognosis, the cell proliferation marker, PCNA, did not exhibit any relation with both treatment end points. Although PCNA is considered to be the ideal marker for cell proliferation, recent studies advocate using Ki-67 (MIB-1) as proliferation marker for prognostic studies as the half-life of PCNA protein is comparatively long and thus cells in a nonproliferative state also may retain this protein. ${ }^{21}$ Hence, we have also analysed the expression pattern of $\mathrm{Ki}-67$ in the sections of the same sample available with us in order to see whether Ki-67 has any prognostic significance in these samples. A total of 112 samples were stained for Ki-67 and the expression pattern showed significant correlation (coefficient $=0.543$; $P=<0.001$ ) with the expression pattern of PCNA. Like PCNA, Ki-67 expression also did not show any significant association with disease-free survival or overall survival. Thus, the results showed that proliferation rate of the tumours may not influence the treatment response.

We also examined the combined influence of p16 and cyclin D1 expression on the prognosis of the patients. The subgroup having a molecular phenotype, cyclin D1 overexpression and low expression of p16 had the lowest survival rate, whereas the subgroup with low expression of cyclin D1 and p16 overexpression had significantly longer disease-free survival and overall survival. The findings of a recent report that cyclin D1 overexpression exerts its oncogenic activity in a CDK4-independent manner and cyclin D3 through CDK4-dependent fashion ${ }^{16}$ leads to the conclusion that simultaneous overexpression of cyclin D1 and low expression of p16 may contribute to overactivation of both these pathways. This may be the reason for the poorest survival in the subgroup showing aberration in both these genes. Thus, maintaining an unimpaired $\mathrm{Rb}$ pathway seems to be a prerequisite for good survival of the patients following the treatment, and aberrations in this pathway act synergistically on the survival, a matter of concern for designing treatment. Bova et al ${ }^{14}$ has also reported reduced diseasefree survival and overall survival among the subgroup of patients with a loss of p16 expression and overexpression of cyclin D1 in tongue carcinoma, which is analogous to the results of the current study. In a more recent report, cyclin D1 amplification and p16 deletion, when taken together, indicated a poorer treatment outcome than either of the abnormalities alone in HNSCC. ${ }^{22}$ Our previous report also demonstrated that p16 and cyclin D1 were significant biological markers to assess the radioresponse in oral cancer patients. ${ }^{9}$ Cyclin D1 and p16 predicted the survival of the patients comparatively stronger than any of the conventional clinicopathological prognostic markers examined. Therefore, subgrouping the patients based on the molecular phenotype of cyclin D1 and p16, we could identify groups of patients with bad prognosis, and this might be of clinical utility in designing treatment modalities.

Among the p53 pathway proteins studied, p53 overexpression showed significant association with poor survival in univariate analysis. However, it did not show independent influence on the survival of the patients by multivariate analysis. We evaluated p53 expression using two clones (clone DO-7 and clone Pab 240). Immunohistochemically, p53 could be assigned as wild or mutant type, based on its expression pattern using antibodies DO-7 and Pab240 under nondenaturing conditions. ${ }^{23}$ This again is based solely on the mutant-specific conformational alteration of certain specific regions on the p53 protein. Although we utilized formalinfixed, paraffin-embedded section (denatured) for immunohistochemical technique, we noticed prominent difference in p53 expression detected with clone DO-7 and clone Pab240 antibodies. From this, we assume that positivity using Pab240 expression indicates mutant p53 even in the denatured condition. We had reported earlier that p53 overexpression detected by mutant-specific Pab240 can independently predict the local treatment failure in conventional fractionation of radiotherapy protocol and not in altered fractionation schedule. ${ }^{9}$ Conventional fractionation is expected to activate selectively p53-mediated apoptotic pathway in the tumour cell. Hence, patients with mutant-specific p53 overexpression should be considered for other treatment modalities. Several studies reported a positive relation between the alterations in p53 gene and poor prognosis in head and neck cancer patients. $^{24-28}$ However, in the present study, we could not find any independent influence of p53 on prognosis in oral cancer patients. This may be because we analysed the important proteins of both pathways, p53 and $\mathrm{Rb}$, together to determine the prognostic efficacy and, therefore, the Rb pathway proteins proved to be independent over the p53 pathway proteins in the multivariate analysis. The other studies mentioned above have also analysed the p53 protein or the proteins involved in the p53 pathway to determine its prognostic influence and some of them demonstrated the significant role of these proteins as prognostic markers. ${ }^{24-28}$ However, some previous reports did not find any prognostic significance of p53 in head and neck cancers. ${ }^{29}$ Recently, Balz et $a l^{30}$ reported that $95 \%$ of the head 
and neck cancers lack normal p53 function and concluded that inactivation of p53 per se is not a suitable choice as a prognostic or predictive marker.

Since prognosis has a multifactorial molecular background, it is important to look for a battery of markers for its influence on the prognosis of the patients in a larger cohort. In the present study, the above criteria were satisfied by analysing multiple components of the $\mathrm{Rb}$ and p53 pathway proteins for their prognostic value in a significantly large patient population and demonstrated that $\mathrm{Rb}$ pathway proteins like cyclin D1 and p16 are beneficial in predicting prognosis. Watanabe et $a l^{31}$ had analysed the prognostic significance of Rb and p53 pathway components at molecular level in astrocytomas and found that aberrations in the p53 pathway are more important than those in the $\mathrm{Rb}$ pathway in prognosis. The present study also stresses the need for the simultaneous analysis of a battery of proteins involved in the major pathways in cell cycle regulation to find out the most important ones for the prognosis.

Even though the $\mathrm{Rb}$ and p53 pathways are interconnected, the present study demonstrated that the $\mathrm{Rb}$ pathway proteins are more important than the p53 pathway proteins for the prognostication of oral carcinoma patients. It was also seen that more than one aberration among the components of the $\mathrm{Rb}$ pathway has an additive effect, leading to poor survival of the patients. The alterations in the $\mathrm{Rb}$ pathway proteins, like cyclin D1 overexpression and low expression of p16, were associated with reduced survival and act as independent prognostic variables, which can supplement conventional clinical prognostic markers. The combined evaluation of p16 and cyclin D1 in oral carcinoma also identified a group of patients with the worst survival who should be considered for alternate or more intense treatment strategies. Thus, in the present study, Rb pathway proteins cyclin D1 and p16 emerged as the most promising molecular prognostic markers in oral carcinoma.

\section{Acknowledgements}

This work was supported by the Indian Council of Medical Research through their research Grant, ICMR No. 5/13/24/96-NCD-III.

\section{References}

1 Parkin DM, Muir CS, Whelam SL, et al (eds). Cancer Incidence in Five Continents. Volume VI. International Agency for Research on Cancer: Lyon, 1992.

2 Moore SR, Johnson NW, Pierce AM, et al. The epidemiology of mouth cancer: a review of global incidence. Oral Dis 2000;6:65-74.

3 Silverman Jr S. Demographics and occurrence of oral and pharyngeal cancers. The outcomes, the trends, the challenge. J Am Dent Assoc 2001;132(Suppl):7S-11S.
4 Sherr CJ. Cancer cell cycle. Science (Washington DC) 1996;274:1672-1677.

5 Okami K, Reed Al, Cairns P, et al. Cyclin D1 amplification is independent of p16 inactivation in head and neck squamous cell carcinoma. Oncogene 1999;18:3541-3545.

6 Weinberg RA. The retinoblastoma protein and cell cycle control. Cell 1995;81:323-330.

7 King KL, Cidlowski JA. Cell cycle and apoptosis: common pathways to life and death. J Cell Biochem 1995;58:175-180.

8 Li Y, Jenkins C, Nichols M, et al. Cell cycle expression and p53 regulation of the cyclin-dependent kinase inhibitor p21. Oncogene 1994;14:31-35.

9 Jayasurya R, Francis G, Kannan S, et al. p53, p16 and cyclin D1: molecular determinants of radiotherapy treatment response in oral carcinoma. Int J Cancer 2004;109:710-716.

10 Todd R, Hinds PW, Munger K, et al. Cell cycle dysregulation in oral Cancer. Crit Rev Oral Biol Med 2002;13:50-61.

11 Classon M, Harlow E. The retinoblastoma tumour suppressor in development and cancer. Nat Rev Cancer 2002;2:910-917.

12 Ruas M, Peters G. The p16 ${ }^{\mathrm{INK} 4 \mathrm{a}} / \mathrm{CDKN} 2 \mathrm{~A}$ tumour suppressor and its relatives. Biochem Biophys Acta Rev Cancer 1998;1378:115-177.

13 Masuda M, Suzui M, Yasumatu R, et al. Constitutive activation of signal transducers and activators of transcription 3 correlates with cyclin D1 overexpression and may provide a novel prognostic marker in head and neck squamous cell carcinoma. Cancer Res 2002;62:3351-3355.

14 Bova RJ, Quinn DI, Nankervis JS, et al. Cyclin D1 and p16INK4A expression predict reduced survival in carcinoma of the anterior tongue. Clin Cancer Res 1999;5:2810-2819.

15 Coqueret O. Linking cyclins to transcriptional control. Gene 2002;299:35-55.

16 Lamb J, Ramaswamy S, Ford HL, et al. A mechanism of cyclin D1 action encoded in the patterns of gene expression in human cancer. Cell 2003;114: 323-334.

17 Miracca EC, Kowalski LP, Nagai MA. High prevalence of p16 genetic alterations in head and neck tumors. Br J Cancer 1999;81:677-683.

18 Esteller M, Corn PG, Baylin B, et al. A gene hypermethylation profile of human cancer. Cancer Res 2001;61:3225-3229.

19 Pande P, Soni S, Kaur J, et al. Prognostic factors in betel and tobacco related oral cancer. Oral Oncol 2002;38:491-499.

20 Danahey DG, Tobin EJ, Schuller DE, et al. p16 mutation frequency and clinical correlation in head and neck cancer. Acta Otolaryngol 1999;119: 285-288.

21 Roskell DE, Biddolph SC. Proliferating cell nuclear antigen expression grossly over-estimates cellular proliferation in cardiac myxomas. Eur J Med Res 1999;26:105-106.

22 Namazie A, Alavi S, Oiopade OI, et al. Cyclin D1 amplification and p16 (MST1/CDK41) deletion correlate with poor prognosis in head and neck tumors. Laryngoscope 2002;112:472-481.

23 Stephan CW, Lane DP. Mutant confirmation of p53: precise epitope mapping using a filamentous phage epitope library. J Mol Biol 1992;225:577-583. 
24 Mineta H, Borg A, Dictor M, et al. p53 mutation, but not overexpression, correlates with survival in head and neck squamous cell carcinoma. Br J Cancer 1998; 78:1084-1090.

25 Shin DM, Lee JS, Lippman SM, et al. p53 expression: predicting recurrence and second primary tumors in head and neck squamous cell carcinoma. J Natl Cancer Inst 1996;88:519-529.

26 Rayband-Diogene H, Fortin A, Morency R, et al. Markers of radioresistance in squamous cell carcinoma of the head and neck: a clinicopathologic and immunohistochemical study. J Clin Oncol 1997;16:1030-1038.

27 Caminero MJ, Nunez F, Suarez C, et al. Detection of p53 protein in oropharyngeal carcinoma. Prognostic implications. Arch Otolaryngol Head Neck Surg 1996; 122:769-772.
28 Yao L, Iwai M, Furuta I. Correlations of bcl2 and p53 expression with clinicopathological features in tongue squamous cell carcinomas. Oral Oncol 1999;35:56-62.

29 Gleich LL, Salamone FN. Molecular genetics of head and neck cancer. Cancer Control 2002;9:369-378.

30 Balz V, Scheckenbach K, Götte K, et al. Is the p53 inactivation frequency in squamous cell carcinomas of the head and neck underestimated? Analysis of p53 exons 2-11 and human papillomavirus 16/18 E6 transcripts in 123 unselected tumor specimens. Cancer Res 2003;63:1188-1191.

31 Watanabe T, Katayama Y, Yoshino A, et al. Deregulation of the TP53/p14 ${ }^{\mathrm{ARF}}$ tumor suppressor pathway in low grade diffuse astrocytomas and its influence on clinical course. Clin Cancer Res 2003;9: 4884-4890. 